\title{
Ken Bugul y su llegada a Europa: género y humor en Le baobab fou*
}

\author{
Isabel Esther GONZÁLEZ ALARCÓN***
}

\begin{abstract}
Resumen
Por medio del análisis de la novela Le baobab fou, vamos a conocer, de la mano de la escritora senegalesa, Ken Bugul, y a través del humor, la emancipación de la mujer africana y su visión respecto a la tradición así como el cambio de costumbres que comenzó a producirse a partir de las independencias africanas en 1960 en Senegal, planteando así, de este modo, la teoría del humor desde una perspectiva sociocultural.
\end{abstract}

Palabras clave: Ken Bugul, Le Baobab Fou, Viaje, Género, Humor.

\footnotetext{
* Recibido el 07marzo 2020, aceptado el 15junio 2021.

** Profesora Titular de Universidad, Universidad de Almería, Almería, España. igonzale@ual.es / https://orcid.org/0000$\underline{0001-8670-8584}$
} 


\section{Ken Bugul y su llegada a Europa: género y humor en Le baobab fou}

Una lectura profunda de las obras africanas revela una constante en todas ellas: el humor y la ironía. Estas dos figuras están presentes en la literatura francófona africana desde sus inicios, aunque en la actualidad se está produciendo un uso cada vez más frecuente. Existe una voluntad por parte de los escritores y escritoras de desmarcarse del universo novelesco que ellos mismos han creado. Frente a situaciones trágicas e insostenibles, deciden usar la risa en su escritura como bálsamo al dolor social que detalla. Para comprender bien este fenómeno, tendremos que analizar la construcción de personajes y los contextos en los que se producen estas situaciones humorísticas. Un punto de referencia importante en nuestro estudio han sido las novelas del África francófona subsahariana de la época de la colonización, como Monné, Outrages et Défis (1990) de AhmadouKourouma, o Le VieuxNègre et la Medaille (1956) de Ferdinand Oyono.

En ambas obras veremos cómo la parodia se torna en un arma, una crítica, cómo pasa a convertirse en una risa que, partiendo de momentos realmente trágicos, desemboca en una situación absolutamente cómica:

En realidad, la función de lo grotesco es liberar al hombre de las formas de necesidad inhumana en que se basan las ideas convencionales. Lo grotesco derriba esa necesidad y descubre su carácter relativo y limitado. La necesidad se presenta históricamente como algo serio, incondicional y perentorio. En realidad, la idea de necesidad es algo relativo y versátil. La risa y la cosmovisión carnavalesca, que están en la base de lo grotesco, destruyen la seriedad unilateral y las pretensiones de significación incondicional e intemporal y liberan a la vez la conciencia, el pensamiento y la imaginación humanas, que quedan así disponibles para el desarrollo de nuevas posibilidades (Bajtín, 1971:50).

Bajtín hace referencia a la situación graciosa, reconociendo el origen social de la misma, en donde mantiene el poder simbólico en el escenario social.

El humor es un modo de ver el mundo, de representarlo. También es una manera de ser del individuo, del ser humano con respecto a la sociedad, como bien lo explicita Noguez en sus palabras:

Es una estrategia, en efecto es una estrategia contra la adversidad. Prohibiéndose la reacción afectiva negativa, el miedo, la cólera, el sufrimiento o la desesperación, que es lo que se esperaría por otra parte, el humorista guarda su flema y crítica para una broma. Es por lo que René Le Senne, en su Traité de caractérologie, hace de ello una particularidad de los flemáticos -seres activos y secundarios relativamente desprovistos de emotividad : en su esencia, explica él, el humor consiste en transferir sobre el plano de la inteligencia lo que debería quedarse sobre el plano de la emotividad. ¿Un hombre puede sentirse fuertemente emocionado por algún acontecimiento que haya vivido? El humor consiste en presentar un acontecimiento como un elemento del orden del mundo. ${ }^{1}$

Estamos en la convicción de que el humor es un fenómeno sociocultural. Esta será la premisa de nuestro estudio. Pocas investigaciones existen sobre este como categoría. Encontramos en ellas a Baudelaire en Lo cómico y la caricatura (1988) o a MijailBajtin en La cultura popular en la Edad Media y el Renacimiento (1974). También hallamos otros trabajos como el de Manuel González y Sergio Fernández en La caricatura política o el de Maurice Blanchot, La risa de los dioses, el de Eça de Queiroz en La decadencia de la risa y el de Alfred Stern en Filosofía de la risa y del llanto:

\footnotetext{
1 “C'est une stratégie, en effet, une stratégie contre l'adversité. S'interdisant la réaction affective négative, peur, colère, souffrance ou désespoir, que l'on attendrait, l'humoriste garde son flegme et réplique par une plaisanterie. C'est pourquoi René Le Senne, dans son Traité de caractérologie, en fait une particularité des flegmatiques - êtres actifs et secondaires relativement dépourvus d'émotivité : Dans son essence, explique-t-il, l'humour consiste à transférer sur le plan de l'intelligence ce qui devrait être sur le plan de l'émotivité. Un homme est-il en passe d'être violemment ému par un événement auquel il assiste ? L'humour consiste à présenter cet événement comme un élément de l'ordre du monde" (Noguez, 2000:15). (Todas las citas han sido traducidas por la autora del artículo).
} 
Pero no es necesario señalar que no existen muchos esfuerzos científicos orientados directamente al tratamiento del humor como categoría. Uno de esos estudios pertenece a Mijail Bajtín (1971), autor de La cultura popular en la Edad Media y el Renacimiento, otro es el de Charles Baudelaire (1989) cuya obra Lo cómico y la caricatura es frecuentemente citada en las investigaciones relacionadas al tema del humor. El trabajo de Robert Escarpit (1962), autor de El Humor, no es menos importante. Sin embargo, el análisis y uso de algunos conceptos como lo grotesco, la fealdad, la degradación, etc. no han sido sino ensayos de una aproximación teórica con el propósito de construir categorías "propias". La risa, por ejemplo, no es considerada para la comprensión del humor sin que sea aceptada como un elemento ajeno aún a los dominios de este, que se presenta regularmente como un fenómeno con vida propia con una configuración propia. (Yupanqui, 2008:249).

Nuestra intención aquí, es plantear la teoría del humor desde una perspectiva sociocultural, es decir, sacar a escena el humor, representándolo como un complejo fenómeno sociocultural (Bergson, 1939:58).

Podríamos decir que todo lo cómico no es, pues, todo aquello que produce risa. Aunque por lo general existe la tendencia de confundir lo cómico con lo humorístico, es necesario marcar sus diferencias. Mientras que lo cómico desciende de la comedia, el humor es un fenómeno sociocultural. En distinto lugar se halla la ironía, una figura retórica, complementaria, que sitúa al signo, frente a frente con el símbolo y en donde la palabra representa un significado distinto al literal. La ironía es una reflexión, en la cual, la burla pasa a ser la protagonista de la acción, algo así como el "humor negro" del que habla Eduardo Stilman (1967). Una reflexión que recurre al desprecio desde una mirada absorbente (1967:248), un desprecio que no observamos en la percepción que Bugul tiene de la civilización europea, pero que sí hallamos en la visión que Kourouma nos da sobre la sociedad africana y sus jefes políticos africanos en Monné, Outrages et Défis (1990) o en Enattendant le vote des bêtessauvages (1998). ${ }^{2}$

Diferentes contextos y escenarios socioculturales pueden producir errores de interpretación de la realidad. Es ahí donde tiene cabida el humor, como veremos en nuestro artículo, en donde el lector accederá a una doble relación entre Europa y África, por medio de la escritora senegalesa, Ken Bugul, y su mirada virgen tras descubrir Occidente por primera vez.

¿Por qué hemos escogido el género literario de la novela como objeto de estudio, paradójicamente, el más alejado de la tradición literaria africana? Tal elección se debe a que es, sin duda, la novela, la encargada de iniciar la andadura de la literatura africana escrita en lenguas europeas y porque en ella se han reflejado las nuevas sociedades africanas, una sociedad en mutación que pone en entredicho sus tradiciones. Cuestionar la tradición como elemento que impide la modernización de esa sociedad tribal es un tema capital de la novela africana, y escritoras y escritores lo harán generalmente a través de sus personajes. Eso es precisamente lo que vamos a presenciar en las escenas llenas de ingenuidad que nos muestra Bugul en Le baobab fou (1982) tradición frente a modernización, sorpresa y estupefacción en el puente de paso entre la tradición africana y la recién descubierta civilización europea, por medio de la visión que nuestra escritora niña hace llegar al lector, tras su llegada a Europa.

Ken Bugul fue la última hija de una familia numerosa. Abandonada por su madre a los cinco años de edad y viviendo con un padre mayor de 85 años, tuvo una infancia marcada por la soledad y la separación de su progenitora, abandono que ella misma detalló y relató en Le baobab fou (1982).

Apasionadas por el porvenir, las escritoras africanas escriben el principio de su camino en tiempos de sus madres. Haciendo de la lengua francesa su casa de escritura, hacen tambalear las

\footnotetext{
2 El humor y la ironía, aplicados a situaciones coloniales y postcoloniales, difíciles e insostenibles, permitieron, al citado escritor marfileño, poder redactar, a modo de denuncia, un discurso político en donde caricaturizaba, desde la ficción, a dictadores políticos africanos reales y en donde hablaba de todo el sufrimiento que, tanto colonizadores franceses, como dirigentes autóctonos, ocasionaron a la sociedad africana.

3 A esta primera novela le siguieron Cendres et braises (1994), Riwanou le chemin de sable (1999), La Folie et la mort (2000), De l'autrecôté du regard (2003), Rue Félix-Faure (2005), La Pièced'or (2006), Mes hommes à moi (2008), Aller et Retour (2014) y Cacophonie (2014).
} 
fronteras, eligiendo ser mujeres de dos o más orillas y caminar al encuentro de horizontes y de lectores nuevos. Es, sin duda, la inmensa fuerza de la tinta y de la página que redefine así las fronteras y las abre al mundo. Compartir la lengua francesa crea a esta vasta comunidad femenina de escritura y de ser, el lugar donde encontrarse, por encima de las ideas preconcebidas.

Como objetivo principal en este trabajo nos planteamos el hecho de proyectar una mirada sobre la literatura del África francófona tomando como base de estudio el humor desde una perspectiva sociocultural en la literatura escrita por mujeres.

¿Por qué Senegal ha sido nuestra elección y no otro país subsahariano, y por qué esta novela? Porque a través del análisis de la obra Le baobab fou vamos a conocer la emancipación de la mujer y su visión respecto a la tradición, así como el cambio de costumbres que comenzó a producirse a partir de las independencias africanas en 1960 en Senegal.

Usar la novela como medio de expresión es emitir mensajes a un posible lectorado, es participar en ese intercambio escritor/a-lector/a, narrador-narradora, lectores/as-autores/as. Una lectura atenta de las obras africanas revela una constante en todas ellas: la risa expresada a través del humor y la ironía. Estas dos figuras están presentes en la literatura francófona africana desde sus inicios. Sin embargo, algunos autores como Ossouma, critican este aspecto lúdico del humor en la novela africana de nueva generación, por su aspecto carnavalesco. Otros, como Kourouma, en cambio, ensalzan a los escritores que han hablado en tono sarcástico del poder colonial, así como $\mathrm{de}$ los dirigentes de las Independencias, luchando de este modo, contra las injusticias sociales. Es sorprendente, que, ante situaciones trágicas, los autores y autoras del Sur del Sáhara, no dejen de utilizar el humor en su escritura, empleando la técnica de la risa como instrumento de protesta y crítica a su realidad, por medio de un lenguaje, en absoluto, agresivo.

En cuanto a la metodología empleada, haremos que ese análisis literario viaje del interior de esas novelas a nuestra realidad, es decir, extraeremos esas vidas narradas de personajes femeninos del África subsahariana para contarlas y darlas a conocer. Para ello llevaremos a cabo la adaptación teatral de dos novelas: Le baobafou (1982), y Riwanou le chemin de sable (2001), en donde la narradora y protagonista de ambas, Bugul, es una joven que ha vivido en Europa y que vuelve a su país africano natal, aceptando de manera voluntaria ser una de las coesposas de un maduro y respetable seriñe en su pueblo natal africano. Se examinarán dos ejercicios de adaptación teatral, el primero de ellos en lengua francesa, trabajando y adaptando los textos originales en ese mismo idioma. El segundo y para una mayor difusión, se llevará a cabo un ejercicio de traducción, interpretando dichos textos en castellano. La adaptación teatral en francés se representará en un contexto académico y universitario, en distintas universidades españolas, así como en Centros de Secundaria bilingües franceses de Almería capital. A su vez, la adaptación teatral en castellano será presentada en distintos pueblos de la provincia almeriense, en días dedicados a la figura de la mujer.

Para comprender bien este fenómeno, analizaremos a los personajes femeninos y sobre todo el contexto en el que estas conviven. La obra teatral que preparamos en estos momentos y cuyo primer acto analizamos en este artículo comprende la adaptación teatral de Le baobab fou (1982) y Riwanou le chemin de sable (2001), que corresponderían al primer y segundo acto, respectivamente. La primera parte, centrada en la adaptación de la primera ( $L e$ baobab fou) presenta la estructura de un monólogo, en donde la escritora nos cuenta, estupefacta, sus primeras impresiones y sorpresas, llenas de ignorancia y descubrimiento, a su llegada a Europa, procedente de su pueblo natal africano. Nuestro análisis aquí, tendría como objetivo exclusivo esta primera parte, este primer acto, el estudio minucioso de esta, su primera novela, en el que damos a conocer la emancipación de la mujer africana y su visión respecto a la tradición y el cambio de costumbres, a través del humor. En dicho monólogo, la protagonista, como único personaje, entra a escena y confiesa a ese público variado, durante ese primer acto, todas las vivencias que experimentó tras su llegada, en busca de horizontes nuevos, a Bélgica ${ }^{5}$.

\footnotetext{
4 Jefe o guía espiritual en las comunidades musulmanas de Senegal.

${ }^{5}$ La segunda parte, que sería la adaptación teatral de la novela Riwanou le chemin de sable (2001) entraría a formar parte del segundo acto de la obra, en donde la poligamia se convierte en el eje central y, por consiguiente, un tema que correspondería a otro trabajo distinto y posterior, tan importante como este, pero en donde el humor no tendría cabida.
} 


\section{Género y humor en Le boababfou...}

Partiendo de Ferdinand Oyono llegamos a la conclusión de que la risa no es algo nuevo en la literatura africana. Bien al contrario, esta se encuentra presente desde los inicios de la misma. Su presencia ha ido creciendo a medida que la literatura subsahariana ha avanzado en el tiempo. Sin embargo, antes de comenzar con el análisis propiamente dicho de Le baobab fou debemos concretar la noción del humor y de la ironía desde perspectivas distintas: ¿Cuál es el origen y la relación entre ambos términos? ¿La ironía es un componente del humor? ¿Cuál es la relación que el humor y la ironía tienen con lo que es serio y con lo que no lo es?

El fenómeno de la risa no es sólo un hecho que nace de lo cómico sino también del humor y la ironía. Sin embargo, no es lo mismo humor que ironía. El término humor hizo su aparición en Francia en el siglo XVIII, siglo a partir del cual una teorización del término propiamente dicho comenzó a ser una realidad. Si consideramos el humor bajo el ángulo propiamente dicho del lenguaje, es posible asociarlo a diferentes niveles del discurso, pudiendo así hablar de un discurso serio y no serio. El humor es la consecuencia de la oposición entre ambos, es un efecto de contraste, de contradicción entre estos dos registros. Tanto este como la ironía son realidades de un lenguaje que emanan de la percepción del mundo. Según la mirada con la que se proyecte esa realidad se empleará bien el humor, bien la ironía.

Más allá de las consideraciones filosóficas y psicológicas, la ironía es también una forma estética, una manera de ver y de concebir la realidad. Es este aspecto crítico el que emplea a menudo la literatura africana. A nivel literario, la ironía es una forma retórica muy empleada, es una técnica de puesta en escena, entre la realidad y su representación. A través de la ironía el artista, como bien dice Schontjes (2001:109)., se libera, pudiendo representar una cosa y su contrario:

El arte se muestra con la finalidad de hacer posible una visión renovada de la realidad: el artista se esfuerza en presentar una verdad original de las cosas ocultando su aspecto convencional, que pasa por su representación tradicional. Para renovar la visión del mundo, tendrá pues que, simultáneamente, negar lo que el objeto posea de convencional, y volverlo a crear. El recurso a la ironía permite dar paso al primer momento, necesario para acceder al segundo: la creación original, liberada de censuras. ${ }^{6}$

Como observamos en las palabras de Schontjes, la ironía representa un juego de miradas, una reflexión sobre la imagen propiamente dicha. Esta posiciona a imagen y a pensamiento frente a frente, creando un desdoblamiento entre lo idéntico y lo opuesto...entre el personaje y su reflejo.

El empleo de la ironía en la literatura africana es una técnica muy frecuentada por escritores africanos (hombres). Entre ellos destacamos la figura de Kourouma en sus novelas Les Soleils des Indépendances (1980) y Monné, Outrages et Défis (1990), donde antiguos jefes dinásticos tribales y dictadores son irónicamente caricaturizados por el autor, manifestando así su desacuerdo frente a los sistemas de gobierno impuestos en el continente africano.

Siguiendo la distinción de Noguez en la diferencia entre humor (amor) e ironía (desprecio) ${ }^{7}$, separamos el humor que producen los autores del que crean las autoras africanas. Si el de los escritores se acerca más a la ironía, en su protesta política por el sistema social establecido en África, el empleado por las escritoras está más próximo al humor. Estas lo usarán como arma literaria para denunciar una sociedad patriarcal en donde la mujer es considerada como un objeto sexual y de intercambio en el matrimonio. Bugul, así nos lo muestra en su viaje a Europa, un viaje que ella misma nos relata en Le baobab fou....

\footnotetext{
6 "L'art se montre afin de rendre possible une vision renouvelée de la réalité ; l'artiste s'efforce d'établir une vérité originale des choses en minant leur aspect conventionnel, qui passe par leur représentation traditionnelle. Pour renouveler la vision du monde, il aura donc simultanément pour tâche de nier son objet - dans ce qu'il a de conventionnel -et de le recréer. Le recours à l'ironie permet de réaliser le premier moment, nécessaire pour accéder au second : la création originale, libérée des contraintes" (Schontjes, 2001:109).

7 "Humour, c'est l'amour ; ironie, c'est mépris" [Humor, es amor; ironía es desprecio] (Noguez, 2000:164).
} 


\section{Ken Bugul y su llegada a Europa...}

Era tan diferente el nuevo escenario que le esperaba en Europa, una cultura tan lejana a la suya. El avión era su primer contacto con la nueva civilización. Podemos decir que Europa, a través de los ojos de nuestra escritora, daba a luz a una nueva ciudadana. Por medio de su mirada adolescente de recién llegada, intentando comprender nuestra realidad y su funcionamiento, percibimos los sentimientos contradictorios, llenos de admiración, sobresalto y humor en su primer contacto con la nueva cultura:

Tras el anuncio del despegue, me entraron ganas de salir corriendo hacia el avión. El avión al que yo no osaba mirar. Esa bestia que tantas veces me hizo alzar la cabeza en mi pueblo cuando parecía un pájaro sin alas volando por el cielo -i entonces nosotros lo llamábamos aeroplano! cuando, de pronto, el berrido lejano de un cordero, degollado quizás, me hizo girar la cabeza. ¡Ay Dios!, iabandonaba el suelo que me había visto nacer! El país resplandecía de luz y de sol, y sin embargo, yo tenía tantas ganas de salvarme lejos de allí. Por unos instantes temí que nunca saldríamos de aquel lugar, pero entonces, de unos altavoces, que había que adivinar más que escuchar, salió un voz anónima, pero presente, que lo anunció (Bugul, 2020:40). ${ }^{8}$

Las palabras de la cita "y sin embargo, yo tenía tantas ganas de salvarme lejos de allí", reflejan el deseo de nuestra escritora niña de abandonar África, de salir corriendo en busca de horizontes nuevos. Como ella misma nos confiesa, aunque África era la luz, sin embargo, Ken ansiaba abandonar esa tierra soleada que la había visto nacer. Nuestra escritora es hija de una sociedad africana educada bajo los valores occidentales de la colonia francesa, hija de un matrimonio polígamo, en definitiva, el fruto híbrido de un Senegal recién independizado. Tras la escuela francesa en Ndoucoumane, su pueblo natal, esta se marcha a Dakar, a la universidad, donde continuará sus estudios. Con Bugul se producirá un cambio de costumbres en la mujer africana. Ken representa a esa figura de mujer emancipada que abandona el pueblo natal africano para marcharse a Europa. Nuestra escritora encarna el nuevo modelo de mujer subsahariana, libre $e$ independiente, una figura que caminó en paralelo con el periodo de Independencia en Senegal a partir de 1960. La comparación del avión con un ave, cuando de niña Bugul miraba al cielo contemplando su vuelo, así como el sonido de este en pleno despegue, comparándolo con "el berrido lejano de un cordero, degollado quizás" ${ }^{9}$ hacen más que cómica y tierna la escena. Nuestra narradora dejaba el suelo que la había visto crecer. Su miedo por lo desconocido, por la salida inmediata, por la voz que esta escucha procedente de los altavoces, una voz que la sobresalta, una voz que es anónima y omnipresente:

Después de dos caídas, entré por fin en el aparato. iOh ! Era un glacial y estaba iluminado como una amante tierna en plena noche de luna llena. Aún tiritaba de frío y de nervios. Una chica joven que parecía amable con todo el mundo, me instaló y me lanzó una sonrisa, a la cual yo respondí mecánicamente. Caía al asiento que me recogía, este era confortable y seguro. Yo, mientras, seguía resoplando durante un buen rato y no me calmaba, no terminaba de liberarme de esa sensación. Notaba mi corazón cómo latía en mi pecho. Sentí el ruido de los reactores como si rodaran barriles vacíos. Cuando todos los pasajeros, a los cuales no presté ninguna atención, fueron instalados y el despegue se hizo inminente, oímos una voz igual de anónima y suave que la del hall del aeropuerto, la cual, después de darnos una serie de indicaciones $e$ información sobre el vuelo, nos rogó que nos abrocháramos los cinturones, apagáramos nuestros cigarros, subiéramos la bandeja de nuestros asientos y estuviéramos listos para el despegue. Los reactores habían acelerado su movimiento. el aparato comenzó a rodar lentamente, pesadamente, sobre la pista, con su carga de seres, de objetos, de olores, de

\footnotetext{
8 “' A l'annonce du départ, j'eus presque envie de courir vers l'avion. L'avion que je n'osais pas regarder. Cet engin qui $m$ 'avait fait lever la tête combien de fois dans le village quand dans le ciel il ressemblait à un oiseau sans ailes - nous l'appelions "roplane" - lorsque le bélement lointaint d'un mouton, égaré peut-être, me fit retourner la tête. Oh Dieu, je quittais ce sol qui m'avait vu tomber du ventre de la mère! Le pays était vibrant de lumière et de soleil, et pourtant j'avais tant hâte de me sauver au loin. J'avais peur de ne plus croire au départ immédiat, quand des haut-parleurs qu'on devinait plus qu'on ne les entendait, une voix anonyme mais présente l'annonça' (Bugul, 2020:40).

9 “Le bélement lointain d'un mouton, égaré peut-être!' (Bugul, 2020:40).
} 
recuerdos, de regalos, de vida y de muerte.... yo miraba por la abertura y veía que me iba, observaba que aquella abertura era la ventana más inquietante que nunca jamás había visto. El ruido de los reactores había sustituido al berrido de la oveja. Una música dulce que salía de todos lados me acariciaba los oídos; la brisa fresca del aire acondicionado me alejaba del sol y del calor, a los que yo estaba acostumbrada, pues yo sólo conocía eso. Después de haber rodado durante algunos minutos sobre la pista, el avión se paró. No comprendía el por qué de ese parón y fue en ese momento, cuando mis tímpanos, parecía que iban a reventar, ante el despegue de verdad (Bugul, 1982:40-41). ${ }^{10}$

El avión es un lugar glacial, nuestra protagonista pasa del calor del pueblo africano al frío del nuevo mundo que la espera. Con su corazón encogido por la emoción, se extraña de la confortabilidad del sillón que la protege. Ni siquiera puede reconocer a la azafata que la atiende, esa joven tan amable y que saluda a todo el mundo. Bugul jamás se había subido a un avión. Todo era tan extraño para ella... todo eso que pertenecía al nuevo mundo que la esperaba, era el puente hacia su emancipación como mujer, lejos de las tradiciones africanas.

Toda representación del mundo o de lo real constituye la mirada que un sujeto proyecta sobre un objeto. De ahí nacen todo tipo de percepciones que van de la objetividad a la subjetividad. Esto, a veces, puede plantear todo tipo de preguntas e interrogantes en función del ángulo desde donde se esté observando. Schopenhauer habla de la representación como una forma distinta de la voluntad:

Espero haber logrado probar de manera segura que este mundo, en el que vivimos y existimos, es a la vez y en todo su ser, voluntad, representación; que la representación supone ya, como tal, una forma, la del objeto y la del sujeto, y que, en consecuencia, esta es relativa, porque si nos preguntamos, qué es lo que queda, una abstracción hecha de esta forma y de todas las que le son subordinadas y que son expresadas por el principio de la razón, este residuo, considerado como diferente en todo, dentro de la representación, no puede ser otro más que la voluntad, es decir, la cosa en sí propiamente dicha (Schopenhauer, 1966:213). ${ }^{11}$

El avión es el punto de unión entre su tierra de origen y el nuevo mundo. Nos hallamos frente al encuentro de África y Europa, del colonizado y colonizador, dos universos totalmente dispares:

La misma voz suave surgió de no sé dónde y me dio un susto de muerte, anunciando el aterrizaje en París en unos minutos. La llegada se parecía a la salida. Los mismos movimientos de los reactores. Me agarré de nuevo al asiento, la misma angustia, me vino entonces a la mente el berrido desesperado del cordero degollado, como por arte de magia. Cerré los ojos hasta que las ruedas no tocaron el suelo de la pista. Los altavoces difundían una música suave y todo el

\footnotetext{
10 “Après deux chutes, je m'engouffrai enfin dans l'appareil. Oh, il était glacial et illuminé tendrement comme une amante par une nuit de lune. Je frissonnai encore plus et du froid et des nerfs. Une jeune fille qui semblait avoir été gentille avec tout le monde m'installa et me fit un sourire auquel je ne pus que répondre mécaniquement. Je m'effondrai dans le fauteuil qui me happait; il était confortable et rassurant. Je soufflai un bon coup, sans pour autant être dégagée, libérée. Mon coeur tambourinait dans ma poitrine. Le bruit des réacteurs me parvenait comme un roulement de barils vides. Quand tous les passagers auxquels je ne faisais aucune attention furent installés et que le départ fut imminent, nous fûmes priés par une voix aussi anonyme que celle du hall de l'aéroport et aussi suave, après un souhait d'accueil et des informations sur le vol, d'attacher nos ceintures, d'éteindre nos cigarettes, de redresser le dossier de notre siège, d'être prêts. Les réacteurs avaient accéléré leur mouvement. L'appareil roula lentement, lourdement, sur la piste, avec son chargement d'êtres, d'objets, d'odeurs, de souvenirs, de cadeaux, de vie et de mort. Je regardais par le hublot et voyais que je partais; je trouvais que le hublot était la fenêtre la plus inquiétante que j'avais jamais vue. Le bruit des réacteurs avait éteint le bêlement du mouton. Une musique douce émergeant on aurait dit de partout me caressait les oreilles; la brise fraîche de la climatisation m'éloignait du soleil et de la chaleur auxquels j'étais habituée, car je n'avais vécu rien d'autre que cela. Après avoir roulé pendant quelques minutes sur la piste, l'avion s'était immobilisé. Je ne comprenais pas pourquoi et c'est à ce moment que mes tympans furent crevés par le vrai départ' (Bugul, 1982:40-41).

11 "J'espère avoir réussi à prouver d'une manière certaine que ce monde, où nous vivons et existons, est à la fois et dans tout son être partout volonté, partout représentation ; que la représentation suppose déjà, comme telle, une forme, celle de l'objet et du sujet, et que par conséquent elle est relative, qu'enfin, si nous nous demandons ce qui subsiste, abstraction faite de cette forme et de toutes celles qui lui sont subordonnées et qui sont exprimées par le principe de raison, ce résidu, considéré comme différent en tout point de la représentation, ne peut être autre que la volonté, c'est-à-dire la chose en soi proprement dite" (Schopenhauer, 1966:213).
} 
mundo comenzaba a coger sus cosas, lo mismo que durante el despegue (Schopenhauer, $1966: 213) .{ }^{12}$

Bugul, medio dormida, no entiende nada de toda esta situación que está viviendo. ¿De dónde pueden venir esas voces que escucha por los altavoces? Ken siente la nueva realidad que le espera, en el momento de su aterrizaje en París. Este medio de transporte aéreo es su primera relación con Occidente. Bugul nos describe, paso a paso, el descubrimiento que experimenta, desde su mirada virgen de adolescente, en su primer contacto con la tierra de los colonizadores. Esa ingenuidad se tiñe de humor y afecto en el relato, cuando esta detalla al lector el nuevo escenario que está presenciando:

El trayecto en bus se hacía en silencio. Cada vez que salíamos de un túnel yo miraba a izquierda y derecha, los edificios gigantes, los almacenes iluminados aunque estuvieran cerrados. Algunos transeúntes, algunos coches, que circulaban y giraban en todos los sentidos, incluso a veces hasta por encima de nosotros. A pesar del cansancio, no podía evitar levantar la cabeza. Era la primera vez que yo veía coches por todos lados y estaba alucinando...¿Era miedo lo que sentía, asombro, o quizás admiración? Todo eso era maravilloso... (Bugul, 1982:40). ${ }^{13}$

El trayecto en autobús, el segundo medio de transporte que la traslada a su lugar de residencia, es el lazo de unión de nuestra protagonista con su nueva vida. El humor impregna toda la escena. Imaginemos a una estudiante africana saliendo de ese túnel desconocido, dentro del autobús que las llevaba, viendo a izquierda y derecha edificios (para ella, gigantes), así como grandes almacenes iluminados, aunque estuvieran cerrados (en su pueblo natal africano eso no era lo habitual). Incluso el miedo, disfrazado de asombro, la invade cuando ve, por primera vez, coches por encima de su cabeza... "sin ser eso causa de muerte", algo que la deja estupefacta, y sin embargo... resultaba maravilloso.

A través de esta parodia, en donde nuestra escritora es la protagonista, accedemos al cambio de costumbres en la vida de una mujer africana, al antes y al después. La elección del personaje narrador en un relato no es casual. Su mirada es importante en la medida en la que esta posee diversas funciones, algunas más explícitas y acentuadas según el objetivo fijado del autor. Gérard Genette, en su obra Figures III, atribuye al narrador cuatro grandes funciones: la función propiamente narrativa, que consiste en contar la historia; la función de organizador del relato; la función fática que establece o mantiene el contacto con el narrador; y la función emotiva, que da cuenta de la implicación del narrador en la historia que cuenta, de la relación que él tiene con la historia (1972:262).

Podríamos hablar de una función emotiva en la descripción que nuestra narradora hace de esa habitación en la que desemboca tras sus primeros momentos en Europa:

Era una pequeña habitación, con una cama pequeña, un armario pequeño, una mesa pequeña, una silla pequeña y encima de la cama, una pequeña cruz, Cristo. Aquella fue la primera vez que imploré a mi país pidiéndole socorro. Tenía miedo de todo aquello que me rodeaba. Sobre todo de la soledad, del frío, del pequeño Cristo encima de la pequeña cama [...] Me fui desvistiendo poco a poco y evitando, con cuidado, mirar al pequeño Cristo, su vientre, sus muslos. Por fin me metí entre las sábanas. Apagué la luz después de algunos suspiros y soplidos, agotada. Sentía al pequeño Cristo encima de mí. Después de un paseo imaginario, me dormí hasta la mañana

\footnotetext{
12 "J'espère avoir réussi à prouver d'une manière certaine que ce monde, où nous vivons et existons, est à la fois et dans tout son être partout volonté, partout représentation; que la représentation suppose déjà, comme telle, une forme, celle de l'objet et du sujet, et que par conséquent elle est relative, qu'enfin, si nous nous demandons ce qui subsiste, abstraction faite de cette forme et de toutes celles qui lui sont subordonnées et qui sont exprimées par le principe de raison, ce résidu, considéré comme différent en tout point de la représentation, ne peut être autre que la volonté, c'est-à-dire la chose en soi proprement dite" (Schopenhauer, 1966:213).

13 "Le trajet en bus se faisait en silence. Chaque fois que nous sortions d'un tunnel je regardais à gauche et à droite, les immeubles géants, les magasins illuminés alors qu'ils étaient fermés. Quelques passants, quelques voitures, qui roulaient et tournaient dans tous les sens, même parfois au-dessus de nous. Malgré la fatigue, je n'avais pas pu m'empêcher de lever la tête. C'était la première fois que je voyais des voitures au dessus de ma tête et cela faisant un drôle d'effet. Etait-ce la peur ou l'étonnement, ou l'admiration? Car c'était merveilleux, on n'en mourrait pas' (Bugul, 1982:40).
} 
siguiente, y bastante bien, la verdad... La cama estaba fría como un glacial al principio, pero pronto se calentó y, bueno, yo me puse cómoda como si estuviera en las faldas de mi abuela. Como una niña, me decía a mí misma (Bugul, 1982:40). ${ }^{14}$

Ya en el empleo del calificativo "petit", repetido una vez tras otra, apreciamos la subjetividad en las palabras empleadas por Bugul ("petite chambre", "petitlit", "petitearmoire", "petite table", "petitecroix", "petitChrist"). La dimensión de las cosas, en esta nueva realidad, es infinitamente menor a lo que nuestra escritora estaba acostumbrada a ver en África. El juego de palabras creado por nuestra narradora-escritora, en esta cita, sobre lo que es gélido (Occidente) y cálido (África) hace intuir al lector, la frontera existente entre estos dos continentes tan lejanos. La cita relata la inmersión de Bugul en ese nuevo mundo occidental donde será una mujer libre y emancipada, lejos de las mujeres tradicionales de su aldea. Ser libre en Europa, para una recién adolescente llegada de África no siempre es fácil. Bugul emplea la risa para describir el asombro de nuestra narradora en ese proceso de adaptación ante la nueva civilización europea, que queda reflejada en esa pequeña habitación de la residencia de estudiantes que pasará a ser su nueva morada, con ese pequeño Cristo semidesnudo en la cabecera de su cama. La dimensión del espacio sobre lo que es amplio (África) y pequeño (Europa) representa el paso de la sumisión como mujer, en África, a su liberación en Occidente.

En este sentido podríamos mencionar a Voltaire en L'Ingénu(1990) y a Montesquieu en Les Lettrespersanes (2006) cuando hablaban de la ignorancia, la ingenuidad nata, la imagen de lo primitivo, como estrategia narrativa o a Mongo Béti en Désird'Afrique (2002) que utiliza la pureza de la infancia para denunciar las incoherencias de la civilización europea. Primitivo y adolescente son dos calificativos que caracterizan el relato de nuestra narradora en esta Escuela católica femenina, ignorante de todo símbolo político, religioso y cultural con los que el resto de ciudadanos europeos sí se sienten identificados. De ahí parte el humor que encierra el discurso de Bugul, de la ingenuidad de sus palabras:

Todo el mundo actuaba como autómatas (...) Caminaba por las calles. Qué rápido iba la gente, toda aquella gente. Y yo que estaba acostumbrada a sumergir mis pies en la arena caliente y reconfortante. iCómo caminaban aquí todos tan rápido!, y yo parecía un gato montés saltando de arbusto en arbusto. Me empujaban, a veces me mandaban de un lado para otro. Tuve que pararme varias veces para intentar escabullirme de esas personas que corrían casi en todo los sentidos. Y ni siquiera se percataban de mi existencia. ¿Qué pasaba aquí ? ¿Es que se había propagado un incendio ? ¿Era el fin del mundo o qué ? ¿No me habéis visto o qué ? ¿Es que no me véis? iQue soy yo! (Bugul, 1982:55). ${ }^{15}$

Parecía un mundo como perseguido por algún monstruo. A todo lo largo de las calles y de las avenidas, no andabas más de cien metros cuando ya veías un bar, un salón de té, un pub, un restaurante. La gente entraba corriendo y se instalaba dentro, otros salían corriendo, no tenían ni tiempo para tomarse un respiro, pareciera que estuvieran en una maratón sin fin (...) ¿Y Por qué no me saludaban? Incluso entre ellos no se saludaban... Yo no entendía nada. Tenía que,

\footnotetext{
14 "C'était une petite chambre, avec un petit lit, une petite armoire, une petite table, une petite chaise et au dessus du petit lit, une petite croix, le Christ. Pour la première fois, j'appelais chez moi, je criais au secours. J'avais peur de tout ce qui m'entourait. Surtout la solitude, le froid, le petit Christ au-dessus du petit lit [...].

Je m'étais déshabillée en évitant soigneusement de regarder le petit Christ suspendu au-dessus du petit lit et qui n'était pas si couvert que ça. Je n'ai jamais compris pourquoi dans la religion catholique, les saints étaient représentés dans des tenues indecentes. Le torse du Christ, son ventre, ses cuisses. Enfin j'avais fini par me retrouver entre les draps. J'éteignis la lumière après quelques soupirs et reniflements, épuisée. Et je sentais le petit Christ au-dessus de moi. Après une promenade dans l'imaginaire, je m'endormis jusqu'au matin, assez bien. Le lit était glacial au début, mais vite il devint chaud et bon et je m'étais mise à mes aises, comme j'avais toujours envie de me mettre sur les cuisses charnues de grandmère. Une enfant, me disais-je à moi-même" (Bugul, 1982:50-51).

15 "Tout le monde s'exécutait comme des automates (...) J'avais avancé dans les rues. Comme ils marchaient vite, ces gens-là. Et moi qui était si habituée à plonger mes pieds dans le sable chaud et réconfortant. Ici tout le monde marchait trop vite. J'avançais aussi nonchalamment qu'un fauve rassasié en promenade dans la brousse. J'étais bousculée, parfois projetée de tous les côtés. Je m'étais arrêtée à plusieurs reprises pour chercher à me faufiler entre ces personnes qui couraient presque dans tous les sens. Et ils ne faisaient même pas attention à moi. "Qu'est-ce qui se passait donc ici? Un incendie s'était-il déclaré, propagé? Était-ce la fin du monde ou quoi? Vous ne m'avez pas vue? Vous ne m'avez pas reconnue? Mais c'est moï' (Bugul, 1982:55).
} 
obligatoriamente, aligerar el paso, si quería salir de esta multitud sin que me pisotearan como un gusano... (Bugul, 1982:53). ${ }^{16}$

Bugul presenta los hechos tal cual ella los percibe. Es decir, da una definición de lo que ve, con un cierto sentimiento de extrañeza. Aquí podemos visualizar a nuestra autora, estupefacta, invadida por una masa de viandantes europeos ocupando las calles. No entiende cómo nadie la saluda, ni cómo no se saludan entre ellos. No encuentra explicación a estas costumbres sociales, para ella nuevas, hecho que llega a provocar la risa en el lector occidental. Este se sorprende de que la visión de la escritora sea la de creer que el hecho de entrar y salir, en y de lugares públicos, se asemeje al ritmo de una "maratón". Esta exageración por parte de la autora, encierra cierto humor en la interpretación de sus palabras, presentando unas calles con gente proyectada en ambos sentidos, con personas corriendo de un lado a otro. El ritmo en las calles europeas puede ser más apresurado que en las vías africanas, sin embargo no a esos extremos como los percibe ella.

El deseo de integración y la necesidad de ternura conducen a Ken a un embarazo no deseado. De nuevo el humor se apodera de las escenas que nos describe Bugul cuando le confirman que espera un bebé:

\begin{abstract}
“-Pues va a ser que sí, está usted embarazada”. Para mí es como si me estuvieran diciendo que tenía un resfriado, que había cogido una corriente de aire entre los omoplatos. Me quedé en silencio como si no hubiera entendido nada. "¿Entonces? - No sé doctor -¿Cómo no vas a saber de quién estás embarazada ? ¿Si es de un Blanco o de un Negro?" Su pregunta me cogió por sorpresa [...] "¿De un Blanco o de un Negro ? ¿Qué pregunta era esa? ¿de un Blanco ? ¿de un Negro ?" Por primera vez me dí cuenta de que una mujer podía quedarse embarazada de un Negro o de un Blanco (Bugul, 1982:70-71). ${ }^{17}$
\end{abstract}

Efectivamente, por primera vez, Bugul se da cuenta de que una mujer podía quedarse embarazada de un Negro o de un Blanco. ¿Y qué era de un Negro? ¿Y de un Blanco? El sarcasmo del ginecólogo que la atiende cuando le cuestiona: "¿Cómo no vas a saber de quién estás embarazada? ¿Si es de un Blanco o de un Negro?" (71) la lleva a plantearse la distancia existente entre ambas razas y continentes, y a sentirse, por primera vez desde su llegada a Europa, diferente, aún habiendo sido educada siguiendo los cánones marcados por la escuela francesa y por esa civilización que la acoge y en donde se siente una mujer libre. En definitiva, podemos decir que el personaje de Bugul encarna la categoría de los africanos colonizados. Su figura demuestra una singularidad particular: roza casi lo ridículo. La representación que ella misma se hace, deja entrever a una colonizada, igual que "millones de hombres arrancados de sus dioses, de su tierra, de sus costumbres, de su vida, de la vida, de la danza y de la sabiduría" (Césaire, 2004:25). ${ }^{18}$

A través del humor en Le baobab fou y de la mano de Bugul, asistimos a la representación de estos dos mundos, el de los privilegiados y dominantes y el de los dominados. Bugul no comprende qué sucede en este nuevo escenario, donde ella es ahora parte activa, el mundo de los poderosos, donde los Blancos aplican de manera instantánea un protocolo que es totalmente desconocido y nuevo para ella. Lo que resulta más interesante, en la descripción de estos dos universos, es esa mirada que esta proyecta sobre la civilización del Otro:

\footnotetext{
16 "Un monde comme poursuivi par quelque monstre. Le long des rues et des avenues on ne marchait plus de cent mètres sans voir un bar, un salón de thé, un pub, un restaurant. Les gens y entraient en courant et il y en avait qui s'installaient, d'autres sortaient en courant; ils n'avaient l'air de prendre que du répit dans un marathon perpétuel (...) Et pourquoi ne me saluaient-ils pas? Même entre eux ils ne se saluaient pas! Je ne comprenais vraiment pas. Je devais absolument presser le pas si je voulais sortir de cette foule qui n'allait pas tarder à m'écraser par terre comme un ver" (Bugul, 1982:53).

17 “-Et oui, vous êtes prise." C'était comme s'il disait que j'avais un rhume ou que j'avais reçu un courant d'air entre les omoplates. Je restai silencieuse comme si je ne l'avais pas entendu ou compris. "Alors? -Je ne sais pas, docteur. Comment vous ne savez pas? C'est un Blanc ou un Noir?" Sa question m'avait prise de court[ ...]Un Blanc ou un Noir? Qu'est-ce que c'était comme question? Un Blanc? Un Noir? Pour la première fois, je me rendais compte qu'une femme pouvait tomber enceinte d'un noir ou d'un Blanc" (Bugul, 1982:70-71).

18 "Millions d'hommes arrachés à leurs dieux, à leur terre, à leurs habitudes, à leur vie, à la vie, à la danse, à la sagesse" (Césaire, 2004:25).
} 
Me había dicho que su madre iba a venir una mañana, y que no me preocupara si esta se mostraba un poco fría conmigo. Aquella mañana, yo me metí en la cama, cosa que cada vez hacía más frecuentemente. La ventana daba directamente a la acera, desde allí gozaba del espectáculo que había en la calle con el desfile de piernas. Piernas desnudas, piernas vestidas, piernas de hombre, piernas de mujer, piernas con falda, piernas con pantalón, piernas ágiles, piernas delgadas, piernas rápidas. Piernas pesadas, gruesas, piernas que arrastraban. Vi unas piernas que dudaban, enfundadas en unas medias de calidad, y entonces supe que era la madre de Louis, jamás la había visto, pues nunca antes fuimos presentadas (Bugul, 1982:74-75). ${ }^{19}$

Nuestra narradora sirve de espejo para revelar los verdaderos motivos y acciones de otros personajes colonizados que llegan a Occidente. Lo real se encuentra condicionado a ojos de la protagonista, por ese desconocimiento de la civilización europea. Las normas que ella conoce, las de su pueblo natal senegalés, no son las mismas que esta observa en Bélgica.

Debido a su educación occidentalizada, el deseo de nuestra narradora es salir de un entorno en el que se encuentra asfixiada, anulada como persona, renovarse y cambiar de aires para descubrirse y poder verse a sí misma en la tierra prometida, que tan bien le venden, cuando es alumna, en la escuela francesa en África. Y así lo hace, trabaja intensamente para poder obtener esa beca que la llevaría a Bélgica. En Le baobab fou conocemos, con escenas teñidas de humor, el mundo occidental, a través de sus ojos, de sus vivencias personales, que siempre vienen acompañadas de una enseñanza, tan consciente e inmediata como inconsciente y más profunda, esa misma que nos hace darnos cuenta de cuánto hemos cambiado, cuando ya hemos culminado un proceso de aprendizaje personal.

\section{A modo de conclusión}

Mientras autores como Kourouma, disfrazando su discurso de un tono irónico y burlesco, pudieron contar y denunciar al mundo lo que sucedía en África, en aquellos momentos de independencia de los países africanos, escritoras como Bugul, en cambio, abandonaron ese tono de burla, de ironía o caricatura en sus relatos.

Siguiendo las palabras de Noguez (2000:164), nos atrevemos a afirmar que el humor que Bugul refleja, en Le baobab fou, es amor, un humor puro, sin segundas intenciones, un humor que se transforma en una técnica de escritura así como en una modalidad de percepción de la realidad.

Si en la primera generación de escritoras africanas de la década de los 70, mujeres africanas anónimas, sin ser conscientes de la relevancia que representaba el hecho de dar voz a sus testimonios, rompían el silencio de sus madres y abuelas, con su simple relato autobiográfico, la generación de escritoras de los años 80, entre las que se encuentra Bugul, denunciaba los problemas que afectaban a las mujeres en su sociedad, lanzando así una señal de revuelta. Una denuncia, hecha sin agresividad y con una gran dosis de humor.

Tras el miedo de nuestra escritora niña por todo lo novedoso que presencia como espectadora a su llegada a la Civilización del Otro, sacamos a escena, la sutileza de nuestra narradora, por convertir el humor en elemento de transición entre el rol de la mujer dentro de la sociedad patriarcal ${ }^{20}$ africana y su papel como mujer liberada en el nuevo mundo que la espera. En definitiva, podríamos decir, que, usando el humor como herramienta literaria principal, asistimos, como lectores, de la mano de Bugul, a ese cambio de costumbres que se produjo en África como consecuencia de las independencias africanas en 1960, en Senegal.

\footnotetext{
19 "Il m'avait annoncé la visite de sa mère pour un matin, en me demandant de ne pas trop m én faire si jamais elle se montrait froide avec moi. Ainsi, ce matin-là, j'étais allongé sur le lit, ce que je faisais de plus en plus. La fenêtre donnant directement sur le trottoir, je jouissais de ce spectacle qu'etait la rue des jambes. Des jambes nues, des jambes habillées, des jambes d'hommes, des jambes de femmes, des jambes en jupe, des jambes en pantalon, des jambes agiles, des jambes minces, des jambes rapides. Des jambes lourdes, grosses, traînantes. Je vis deux jambes hésitantes, serrées dans des bas de qualité, et je sus que c'était la mère de Louis, je ne l'avais jamais vue auparavant, car il n'avait jamais été question que nous soyons présentés" (Bugul, 1982:74-75).

${ }^{20}$ Calificativo que otorga mayor autoridad del varón en un grupo social.
} 


\section{Referencias bibliográficas}

BA, Mariama. Une si longuelettre. Paris, Le Serpent à Plumes, 2001.

BAJTín, Mijail. La cultura popular en la Edad Media y el Renacimiento. Barcelona, Barral Editores, 1971.

BARTHES, Roland. Leçon. Paris, Seuil, 1989.

BAUDELAIRE, Charles. Lo cómico y la caricatura. Madrid, Editorial Visor, 1988.

BERGSON, Henri. La risa. Ensayo sobre la significación de lo cómico. Buenos Aires, Losada S.A, 1939.

BLANCHOT, Maurice. La risa de los dioses. Madrid, Taurus, 1971.

BUGUL, Ken Le baobab fou. Paris, Seuil, 1982.

BUGUL, Ken. Riwanou le chemin de sable. Paris, PrésenceAfricaine, 2001.

CESAIRE, Aimé. Discours sur le colonialismesuivi de Discours sur la Négritude. Paris, Présenceafricaine, 2004.

DE QUEIROZ, Eça. La decadencia de la risa. Madrid, Biblioteca Nueva, 1918.

FERNÁNDEZ, Sergio. Triunfo y secreto de la caricatura. En: GONZÁLEZ, M. (ed.). La caricatura política. México, Fondo de Cultura Económica, 1955, pp.I-XXI.

GENETTE, Gérard. Figures III. Paris, Seuil, 1972.

GONZÁLEZ, Manuel. La caricatura en la revolución. En: GONZÁLEZ, Manuel. (ed.). La Caricatura política. México, Fondo de Cultura Económica, 1955, pp.XXIII-XLII.

INFANTE YUPANQUI, Carlos. Poder, tensión y caricatura. Una aproximación a la teoría del humor. En: Dialogía: revista de lingüística, literatura y cultura, n. 3, 2008, pp.245-272.

KOUROUMA, Ahmadou. En Attendant le vote des bêtessauvages. Paris, Seuil, 1998.

KOUROUMA, Ahmadou. Monné, Outrages et Défis. Paris, Seuil, 1990.

KOUROUMA, Ahmadou. Les Soleils des Indépendances. Paris, Seuil, 1980.

MONGO MBOUSSA, Béti. Désird'Afrique. Paris, Gallimard, Continentsnoirs, 2002.

MONTESQUIEU. Lettrespersanes. Paris, Les classiques de Poche, 2006.

NOGUEZ, Dominique. L'Arc-en-ciel des humours. Paris, Librairiegénéralefrançaise, Livre de poche Biblio/essais, 2000.

OYONO, Ferdinand. Le vieuxnègre et la médaille. Paris, Domaineétranger, 2005 [1956].

OSSOUMA, Bernard. Laideur et rirecarnavalesquedans le nouveauromanafricain. Politiqueafricaine n. 60, décembre 1995, pp.117-128.

SCHONTJES, Pierre. Poétique de l'ironie, Paris, Ed. du Seuil, 2001.

SCHOPENHAUER, Arthur. Le Monde commevolonté et commereprésentation. Paris, PUF, 1966.

SENGHOR, Léopold Sédar. Liberté I. Négritude et Humanisme. Paris, Seuil, 1964.

STERN, Alfred. Filosofía de la risa y del llanto. Buenos Aires, Imán, 1950.

STILMAN, Eduardo. El humor absurdo, Buenos Aires, Brújula, 1967.

THIAM, Awa. La paroleauxNégresses. Paris, Denoël, 1978.

VOLTAIRE. L'Ingénu. Paris, Les classiques de Poche, 1990. 